\title{
Del Estudio General a la Universidad de Estudio General
}

Francisco Javier Yate Rodríguez*

La Orden de los Frailes Dominicos ha conservado a través de los siglos el nombre de Studium Generale para sus centros de formación teológica. También escuchamos que algunas universidades actuales se denominan a si mismas Universidad de Estudio General. Los dos nombres no sólo nos conectan con el siglo XVIII, cuando nacieron tanto las universidades como la Orden de

Predicadores, sino que remiten a una concepción propia de la articulación entre las humanidades, la teología y las ciencias en la pedagogía universitaria. (Fray Buitrago Rojas, O. P., 2003, p. 41)

$\mathrm{E}$ tema de los Estudios Generales y el Estudio General ha sido abordado con bastante interés para comprender los orígenes de la universidad y la evolución de las instituciones de educación superior, eclesiásticas y no eclesiásticas ${ }^{1}$, en el periodo de la Colonia

* Licenciatura en Filosofía y Letras, Universidad Santo Tomás, Bogotá; Maestría en Filosofía Latinoamericana, Universidad Santo Tomás. Magíster de Filosofía Latinoamericana. Docente del Departamento de Humanidades y Formación Integral, Universidad Santo Tomás, Bogotá.

1 Bajo esta denominación se clasifican los estudios superiores en la Colonia por el historiador de la educación José Abel Salazar. 
en América Latina. Los esfuerzos historiográficos de autores como sor Cruz Rodríguez, Águeda en sus obras La Universidad en la América Hispánica o La historia de las universidades hispanoamericanas: período hispánico; Atcon Rudolph, en Principios de la reforma universitaria, quien dedica el primer tomo de su obra a este tema; y en Colombia, el gran universitólogo jesuita Borrero Cabal, Alfonso, La universidad estudio sobre sus orígenes, dinámicas y tendencias, el dominico Fr. Buitrago Rojas, Franklin, El Studium Generale: un lugar de encuentro entre la revelación y las ciencias del hombre, Plata Quezada, William, Vida y muerte de un convento: dominicos y sociedad en Santafé de Bogotá (Colombia) Siglos XVI-XIX, Soto Arango, Diana Elvira, Aproximación histórica a la Universidad Colombiana y Silva Olarte Renán, Universidady sociedad en el Nuevo Reino de Grana$d a$, por citar solo algunos, dan fe de este interés.

Las distintas acepciones dadas a los Estudios Generales o al Estudio General conllevan inevitablemente el problema de los distintos o diversos modos de entenderlos, así como también de las diferentes expresiones de los Estudios Generales o el Estudio General durante la historia de la universidad. Por ello la pregunta fundamental que se pretende desarrollar en el presente capítulo: ¿cuál ha sido la evolución de las expresiones del Estudio General, desde la Studia Generalia a la Universidad de Estudio General?

El método desde el cual se abordará y desarrollará este trabajo es el gramático especulativo, como lo denomina el dominico Mauricio Beuchot para referirse al método de Tomás de Aquino. Dicho método, afirma el autor, consiste en un tratamiento al mismo tiempo filosófico y lingüístico. En otras palabras, será un análisis conceptual aplicado al Estudio General o a los Estudios Generales para demostrar la relación entre dichas variaciones, como de las distintas acepciones y diferentes expresiones, del Estudio General o Los Estudios Generales.

En el aspecto filosófico coincidía con muchos intereses de la actualmente llamada filosofía analítica, y en el aspecto lingüístico 
tenía muchos elementos de la gramática estructural. Constará, en primer lugar, de un estudio del signo en general, como una parte semiótica, ubicada entre la lógica y la psicología, y un estudio del signo lingüístico, con sus dimensiones sintáctica, semántica y pragmática, es decir, de relaciones de corrección o coherencia con otros signos lingüísticos, de correspondencia con los objetos que pretende designar, y de uso por parte de los hablantes, que introducen sus intenciones muy particulares en el habla; es decir, que introduce el aspecto psicológico y hasta sociológico de la lengua. (Beuchot, 2004, p. 53)

\section{¿Studium Generale o Studia Generalia?}

Studia Generalia y Studium Generale no es una distinción meramente casual lingüística-morfológica, sino que deriva en modos distintos de los Estudios Generales y el Estudio General, por tal razón diferenciar entre una y otra expresión permite mostrar esas variaciones, siendo esta distinción no algo somero, sino fundante al momento de diferenciar entre los Estudios Generales y el Estudio General, contrario a lo planteado por el autor del artículo El Studium Generale: un lugar de encuentro entre la revelación y las ciencias del hombre (Fray Buitrago Rojas O. P., 2003) al referirse respecto a la expresión latina: "El plural de Studium Generale en lengua latina es Studia Generalia, por tal motivo en varios apartados se utilizará la expresión de Studium Generale para facilitar la comprensión del lector que no es conocedor del latín" (Fray Buitrago Rojas O. P., 2003, p. 48).

A este respecto, las expresiones latinas en cuestión, y como deja evidenciar el texto Constitutiones, declarationes et ordinationes: $\mathrm{Ca}$ pitulorum Generalium, Sacri Ordinis Fratrum Praedicatorum; por un lado. Studia Generalia (los Estudios Henerales) hacen referencia al neutro plural en nominativo, vocativo o acusativo, y se emplea para referirse 
al grupo de Estudios Generales impartidos en las diversas provincias de la Orden Dominicana; por otro lado, Studium Generale (el Estudio General) corresponde al neutro singular en los casos nominativo, vocativo o acusativo (Estudio General) y refiere al conjunto de asignaturas que constituyen la enseñanza que se da a los futuros lectores, grado otorgado en la formación de los futuros frailes ${ }^{2}$ (Lo-Cicero Cajetano, 1862).

78. Quando in aliquo studio Generali promoventur in Lectores, non debent iterum in sua Provincia examinari, et approbari. ${ }^{3}$

1. In qualibet Provincia, exceptis Graeciae, Daciae, et Terra Sanctae in aliquo Conventu ideoneo sit stadium Generale. ${ }^{4}$

En otras palabras, Studia Generalia y Studium Generale, en el marco del texto de las Constituciones de la Orden de Predicadores, refieren a Los estudios generales o constitutivos del Estudio General, siendo esta una variación y también válida la apreciación realizada por Fr. Franklin Buitrago, O. P. De igual modo, Studia Generalia,

2 Esto de acuerdo al texto Constitutiones, declarationes et ordinationes: Capitulorum Generalium, Sacri Ordinis Fratrum Praedicatorum, traducción realizada por Noel Olaya Perdomo y Dayan Herrera Bernal. Como se puede observar, puede tomarse de modo diferenciador o de modo equivalente, ya que se habla de tener un centro de estudio general en cada provincia o de esos estudios que debían cursar de teología y filosofía que eran las dos grandes disciplinas de la época, estas dos posibilitaban un abordaje de la realidad como totalidad.

3 78. Cuando sean promovidos Lectores en algún Estudio General, no deben ser examinados y aprobados en sus provincias (Lo-Cicero Cajetano). [Traducción propia]

4 1. En cada provincia, excepto de Grecia, de Dacia y de Tierra Santa haya un Estudio General en algún Convento idóneo (Lo-CiceroCajetano). [Traducción propia] 
adjetivo de primera clase ${ }^{5}$, refiere a Los estudios generales y Studium Generale, como adjetivo de segunda ${ }^{6}$ clase, refiere al Estudio General como lugar o centro de estudio de una élite de frailes destacados, y es para hablar de las asignaturas dentro del Estudio General respecto al Studia Particulare.

Por su parte, el jesuita colombiano Alfonso Borrero Cabal, S.J. al referirse al Estudio General o los Estudios Generales, expresa una separación frente a la universitas y a la problemática respecto al collegium. Pero, de igual modo, plantea otra manera de entender Los Estudios Generales:

La expresión studium generale antecedió a la palabra universitas, pero también alusiva al collegium, colectividad, gremio o entidad corporativa intelectual de los siglos XII y XIII. Studium, porque esta palabra conlleva los sentidos de afición, devoción y dedicación apasionada al ejercicio de las letras; y generale porque las personas entregadas en unión anímica y psicológica a tan ardua y elevada labor, procedían de varias nationes o nacionalidades. (Borrero Cabal, 2008, p. 38)

Esta nueva mirada ofrece una perspectiva historiográfica y geográfica, pues aclara la delimitación que a estos anteceden, y en esa medida difieren de la Universitas, siendo los Estudios Generales más cercanos al collegium como colectividad, corporación o gremio. Así mismo, "General", en tanto Generale, como demarcación geográfica, al ser relacionada con la nacionalidad, distanciándose de la

5 Son adjetivos de primera clase los que tienen tres terminaciones (-us, - $a,-u m)$ y declinan sus tres géneros por la primera y segunda declinación.

6 Son adjetivos de segunda clase aquellos que se declinan siguiendo el modelo de la tercera declinación, la mayoría en $i$. Hay adjetivos de una, dos y tres terminaciones, atendiendo al número de terminaciones que presentan en el nominativo singular. 
perspectiva tradicional del Estudio General en la mirada epistemológica para indicar el diálogo o convergencia de saberes y para abordar la realidad como totalidad, siendo entonces esta última acepción más cercana a la distinción entre Studia Generalia (Estudio General) y Studia Particulare (Estudio Particular).

Como consecuencia, Generale puede verse en dos sentidos. Epistemológico, por ser contrario a Particulare, o geográfico, referido a que allí convergían de diversas nacionalidades, distinción profunda entre una y otra, donde la segunda se acerca más a la concepción de Colegio Mayor y la primera al modo contemporáneo de Universidad, pero que va en contravía a la acepción de General en una perspectiva del conocimiento, en tanto mirada de la realidad como totalidad o convergencia de varias ciencias para abordar la realidad, como ya se ha indicado.

También podría darse otra posibilidad que deberá contemplarse en tanto nueva línea interpretativa histórica, y es la de que el estudio general es más cercano a las artes liberales, mientras que la universitas lo es a las facultades. Argumento que será desarrollado más adelante por su importancia.

\section{Del Estudio General a la Universidad}

Hablar del Studium Generale y de la Universitas remite la mirada a la Edad Media, período comprendido entre los siglos V-Xv en Occidente, más aún a la Baja Edad Media (siglos XI-XV), exactamente esa época denominada como Plena Edad Media (siglos XI-XIII); época crucial que se encuadra por el surgimiento de las ciudades, las universidades y la burguesía, tríada que marcó el nuevo panorama de Europa y el surgimiento de lo que Le Goff denomina lo intelectual.

La Escolástica, nombre con el que también se conoce la Baja Edad Media, tiene su configuración desde el Ix y su estabilización en los siglos X y XI, denominado como Alta Escolástica. Su nombre 
viene del latín scholasticus, más aún, de schola, que es traducido co-

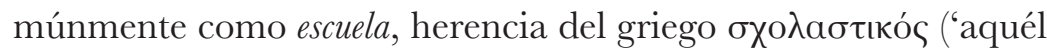
que pertenece a la escuela'), siendo utilizado por primera vez por Platón para referir a $\sigma \chi 0 \lambda \eta ́$ (skholé), llevado al latín como schola, pero que refería al ocio, tiempo libre, estudio; en otras palabras, pasó del cultivo del espíritu o aprovechamiento del tiempo libre (ocio) al estudio en conjunto o grupo, corporación en torno al estudio, pero ya con estatutos y estructura administrativa y luego fisica (Chantraine: 1082-1083).

$\sigma \chi o \lambda \eta ்:$ f. « loisir, tranquilité, temps libre », parfois « répit » [...], parfois «paresse » [...] $\sigma \chi 0 \lambda$ ń peut signifier ce à quoi l'on emploie son temps ou ce qui mérite qu'on l'empoloie, d'où par une évolution remarquable « étude » [...]; d'où finalement dans le grec hellén. et tardif « étude, école philosophique » ${ }^{7}$.

En otras palabras, se habla de Escolástica por la presencia de escuelas canónicas o catedralicias $^{8}$, monacales o conventuales ${ }^{9}$ y las

7 'Ocio, tranquilidad, tiempo libre, 'a veces' respiro '[...] a veces' la pereza “[...] $\sigma \chi 0 \lambda \eta ́$ puede significar que utilizó su tiempo para una evolución notable para "estudiar" [...]; finalmente, en griego, el estudio tardío', y luego escuela filosófica". [Traducción propia] (Chantraine).

8 Se llamaban canónicas o catedralicias, pues allí se formaba el clero regular, hoy denominado como secular. Catedralicia, pues se impartía en la catedral, donde se daba la cátedra a cargo del obispo o a quien él designara. El mayor inconveniente es que era bastante restringido y con un énfasis de formación al futuro clero.

9 Se llamaban conventuales o monacales a los centros dirigidos a la formación de los religiosos o futuros religiosos. Monacal o conventual dependía de su ubicación respecto a la ciudad, pues los conventos son más cercanos, mientras que los monasterios quedaban a las afuera de las urbes. También estaban las abadías, que difieren de los monasterios por su extensión y tamaño, por lo cual tenía una mayor importancia dentro de la jerarquía eclesial y política. 
palatinas $^{10}$ (de pallatium). Cada una con su finalidad, fuera para la formación del futuro clero, religioso o funcionario, las escuelas carecían de una organización sólida y eran más obra de individualidades que de instituciones, la planta física y la figura del rector son propias de finales del siglo XII e inicios del XIII, hasta ese momento, lo más cercano es la figura de la regencia de las cátedras. Eran espíritus libres que se agrupaban para el cultivo de la virtud de la studiositas, aunque eran ya amparados por los nuevos modelos de las agremiaciones o corporaciones de las ciudades. En muchos casos, antes de ser universidades se constituyeron en colegios, tal es el caso del Colegio San Estaban, que luego será la universidad de Salamanca.

La atadura natural de los gremios transitaría por muchas vicisitudes, a veces políticas y de aprovechada demagogia, pero triunfó sobre los atropellos y abusos externos cuando el derecho de los romanos acogió a cada grupo con el nombre de collegium o totalidad de las personas constituidas en entidad jurídica para ejercer actos como poseer y contratar. (Borrero Cabal, 2008, p. 37)

El Studium Generale será algo anexo a las escuelas catedralicias, monacales y palatinas, y antecederá a la Universitas, según Alfonso Borrero, o las universidades nacerán de los Studium Generale, según fray Franklin. En uno y otro caso, son dos caminos diferentes. Ambos autores ubican estas escuelas como antecedentes de las

10 De Pallatium o palcio. Esta emerge en el período Carolingio, cuando Carlos Magno designa a Alcuino de York para pensar una propuesta distinta a la canónica o conventual y él propone este modelo integrando las artes liberales y formulando una educación para las cortes y con posibilidad de acceso a más personas. 
universidades, ambos autores diferencian entre los Estudios Generales y las Universidades.

\begin{abstract}
Mas desde temprano momento (1210-1213), los interesados en enseñar — quienes saben — y por aprender — quienes sabrán-, se sentían muy orondos de ser conocidos y darse a conocer no al modo de un gremio cualquiera, sino como la Universitas por excelencia. Esto lo consiguieron pese a conflictos con el obispo y el Canciller de París, quien lo era de la Universidad. (Borrero Cabal, 2008, p. 37)
\end{abstract}

Studium Generale frente a Universitas se comprenderá mejor desde la importancia que en la Edad Media tuvo el concepto Studium, que era más cercano a Scholla que a Universitas, siendo Studium un concepto propio a la formación o virtud del estudio. En este sentido, la Universitas tendría su antecedente más inmediato en la Schola Scholarium (Escuela de estudiantes) y la Schola Magistrorum (Escuela de maestros), que surgen de las escuelas canónicas o catedralicias, monacales o conventuales y las palatinas, y que se enmarca en la línea de lo propuesto por Borrero respecto a las agremiaciones, donde será primeramente el surgimiento de la universidad como corporación y luego como institución. En otras palabras, primero nació el espíritu de la universidad y luego ella.

Las universidades son originarias de la Edad Media, como ya se indicó, mas alcanzan su madurez en el siglo XIII, tales son los casos de las universidades de París (1040), Bolonia (1050) y la Universidad de Oxford (1167), que emergerán de las escuelas catedralicias. La Universitas Magistrorum et Scholarium serán descendientes de las escuelas catedralicias, monacales y palatinas. Así mismo, son el resultado de aquella dinámica generada durante los siglos XI y XII, en el proceso de las nacientes ciudades, refiérase a la agremiación de artesanos y comerciantes que dio origen a las corporaciones de maestros y estudiantes (Schola magistrorum et Schola Scholarium). 
La conocida expresión universitas magistrorum et scholarium, que data de 1229, denotó sin ambages a un grupo sociológico determinado. Conjunto de personas aglutinadas en torno al oficio del saber. Pocos años antes (1219) se hablaba de Doctorum et discipulorum univesitas y, en 1221, con orgullo y conciencia plena de grupo, maestros y estudiantes de la ciudad se referían a sí mismos con satisfacción y apoteosis: Nosotros, la universidad de maestros y estudiantes residentes en París: Nos universitas magistrorum et scholarium Parisius conmorantium. (Borrero Cabal, 2008, p. 39)

El auge del comercio y los nuevos mercados posibilitaron el nacimiento de una nueva clase social, la burguesía, sin la cual no hubiera sido posible el boom de la construcción, y sin la cual tampoco hubiera sido posible la profesionalización de los oficios y saberes; lo que derivó en la presencia de talleres, y de los cuales emergieron las corporaciones de maestros y estudiantes; siguiendo el modo de organización de los mercaderes, artesanos y comerciantes.

El día en que Abelardo reducido a la miseria comprueba que es incapaz de cultivar la tierra y que tiene vergüenza de mendigar, retorna al profesorado (scolarum regimen). "Retorné al oficio que sabía; incapaz de trabajar con mis manos, me vi reducido a valerme de mi lengua”. (Le Goff, 1996, pp. 68-69)

\section{El Estudio General y las Artes Liberales}

Por otra parte, Studium Generale (Estudio General) guarda un contenido amplio, contrario al Studium Particulare (Estudio particular) o distinto al Studiumseg respectu regni (Estudio respecto al reino); si dicha aprobación y reconocimiento de la institución y de los títulos provenía de autoridades locales y no del pontificado podía, para este tiempo, 
también ser real o imperial. Así mismo, dentro del Estudio General los estudiantes iniciaban con un ciclo de formación común para todas las carreras llamado Artes Liberales, consistente en filosofía, humanidades y la cultura de su tiempo, que a su vez era el encuentro de todo el conocimiento.

Con delicia añeja, graciosa y sabia, Alfonso X explica en Las siete Partidas esta diferencia:

Estudio es ayuntamiento de maestros et escolares que es fecho en algut logar con voluntad et con entendimiento de aprender saberes: et son dos maneras del; la luna es á que dicen estudio general [...] et este estudio debe ser establecido por mandato de Papa, ó emperador ó de rey. La segunda manera es á que dicen estudio particular, que quier tanto decir como cuando algut maestro amuestra en alguna maravilla apartadamente á pocos escolares; et tal estudio como este puede mandar facer prelado ó concejo de algunt logar. (Borrero Cabal, 2008, p. 39)

In secunda medietate saeculi XIII ac deinceps saltem in provinciis maioribus materia studiorum sicut et congregatio studentium diversarum materiarum per speciales conventus distribuebatur 26. Parviores vero provinciae instructionem fratrum suorum quoad facere poterant curarunt, aptiores studentes extra provinciam mittendo. Materia igitur ab exordio in studia theologica vel postea in studia philosophica et theologica dividebatur. Particulares materiae e. G. Iuris in quantum sacerdoti necessariae erant, lectioni theilogicae immiscebantur. ${ }^{11}$ (Walz, 1924, pp. 126-127)

11 "En la segunda mitad del siglo XIII y en adelante, al menos en las provincias mayores, el contenido de los estudios, como también la reunión de los estudiantes de las diversas materias, se distribuía por medio de conventos especiales, pero las provincias más pequeñas se encargaban de la instrucción de sus hermanos en cuanto podían hacerlo enviando a los estudiante 


\title{
Dicha formación de los Estudios Generales se complementaba
} con las artes liberales o siete saberes fundamentales, pero que se dejaba al buen criterio del maestro formador, ya que bajo el argumento de la Auctoritas se vigilaba con bastante rigor la formación de los estudiantes.

Quoniam circa studentes diligens est adhibenda cautela "praeponitur eis aliquis frater specialis (magister studentium) pro moderatione eorum in studii" 4. Si quadrivium pro studentibus nostris non requirebatur 5 , materia studii in ordine non erant scientiae saeculares "nec etiam artes quas liberales vocant nisi aliquando circa aliquos magister ordinis vel capitulom generale voluerit alister dispensare, sed tantum libros theologicos tam iuvenes quam alii legant". "In libris gentilium et philosophorum non studeant etsi ad horam inspiciant". ${ }^{12}$ (Walz, 1924, p. 124)

\begin{abstract}
Ahora bien, frente al argumento de que la Universitas es más cercana a las Facultas y que por lo tanto el Studium Generale lo es a las Artes Liberales, será el punto a dilucidar a continuación. Para esto,
\end{abstract}

más aptos fuera de su provincia. Por consiguiente, el contenido desde el principio se dividía en estudios teológicos o después en estudios filosóficos y teológicos. Las materias particulares, por ejemplo el derecho, en cuanto eran necesarias para un sacerdote, se mezclaban con la lección de teología" [Traducción de Noel Olaya Perdomo y Dayan Herrera Bernal].

12 "Ya que hay que tener un cuidado diligente en relación con los estudiantes, los preside algún hermano especial, a saber, el maestro de estudios para dirigir sus estudios". Si no se necesitaba el cuadrivio para nuestros estudiantes, la materia de estudio en la orden no eran las opiniones mundanas "ni siquiera las artes que llaman liberales a no ser que de vez en cuando acerca de algunos temas el maestro de la orden o al Capítulo General quisiera ordenar algo distinto sino solamente deben leer libros de teología tanto los jóvenes como los demás". "Que no se dediquen a los libros de los gentiles y de los filósofos, aunque los miren a la hora indicada”. [Traducción de Noel Olaya Perdomo y Dayán Herrera Bernal]. 
el paso de las Ars a las Artes Liberales en la Edad Media y el concepto de las facultas son la ruta.

Primeramente hay que decir que para muchos autores, entre ellos Borrero, ars es sinónimo o equivalente a techné:

La palabra ars, por su parte, arranca de raíz helénica que conlleva la connotación de hacer, como equivalente del vocablo techné o artificio producido con fundamento en el saber hacer. Paso a paso, el hacer mismo, o arte se fue diferenciando del cómo hacer razonablemente, en definitiva consolidado en la palabra técnica. (Borrero Cabal, 2008, p. 43)

Frente a este primer argumento, hay que decir que es parcialmente verdadero y parcialmente falso. Parcialmente falso, si se tiene en cuenta el conocimiento o tipo de conocimiento en los griegos, siendo la episteme, la doxa, la techné y la poiesis. A esto sumado, los tipos de saberes en los helénicos; productivos, prácticos y contemplativos. Episteme se refería a conocimiento y para Platón significaba "creencia justificada como verdad", doxa remitía a la "creencia común o mera opinión", techné era "destreza y habilidad", y finalmente poiesis, que era realización, crear algo o la acción de producir un objeto. Por su parte, respecto a los saberes productivos o técnicos estos se concebían como medios para obtener fines; los saberes prácticos, que eran fines en sí mismos, y los saberes contemplativos o teóricos, que eran saber cómo son las cosas.

Cuando se afirma que es parcialmente falso, es referido a esa distinción presente entre techné y poiesis. Techné como destreza y habilidad (tener destreza o habilidad para), mientras poiesis en tanto realización, creación o producción. En otras palabras, no es igual hacer música a ser músico, no es igual hacer poesía a ser poeta. El artista requiere una técnica, pero no se agota en la técnica, es decir, ars es más cercano a poiesis que a la techné, aunque requiere de la techné, por ello es parcialmente falso y parcialmente verdadero. 
También es parcialmente falso respecto a la distinción entre los tipos de saberes. El saber productivo, que es técnico, remitía a la elaboración de cosas útiles; el saber práctico, propendía por la acción libre o electiva y la búsqueda de la virtud; el saber teórico, conducente al modo de ser de las cosas mismas. Además, los saberes productivos remitían al carácter de necesidad, más cuando exigían la satisfacción de ciertas necesidades elementales para mantener la vida, necesidades que demandaban una actividad productiva por parte de los hombres, por ejemplo la arquitectura, la panadería, la medicina, la retórica, entre otros; los saberes prácticos, por el contrario, no se relacionaban con las necesidades de la vida, sino con la posibilidad de una vida buena, tales como la ética y la política; por último, los saberes teóricos, que eran para Aristóteles la mejor de todas las vidas posibles para el hombre libre y que referían a un conocimiento superior.

Los saberes superiores eran un conocimiento superior en el sentido de que tomaban su fundamento de la cosa misma que investigaban y no de los fines que el agente seguía (matemáticas, física, filosofía primera, ciencia del ser en cuanto ser, entre otros). Finalmente, es parcialmente falso, pues ars estaría más próximo a los saberes teóricos, más cuando en los griegos estaba la distinción entre artes serviles o mecánicas, que serían próximas a los saberes productivos, y las artes liberales, que estarían entre los saberes teóricos o contemplativos, por lo cual también es parcialmente verdadero.

Llevados de otras intenciones, incluido el orden social, los antiguos distinguían entre los saberes, los oficios y las dedicaciones del siervo o esclavo, y hablaron de las artes serviles o manuales, en contraste con los conocimientos propios del hombre libre y sus dedicaciones intelectuales: éstas fueron las artes liberales. (Borrero Cabal, 2008, p. 43)

Otro elemento que se debe tener en cuenta y que distancia a Le Goff de Borrero es la presencia y participación en la génesis del 
intelectual, conformación de las corporaciones y nacimiento de la iniveristas, me refiero a los oficios, y, más aún, a la división y especialización de los oficios. Mientras para Le Goff este hecho es fundamental y determinante, para Borrero es incidental o incluso accidental.

Las Artes liberales estará ligado (sic) desde los griegos a los oficios, más en la Edad Media alcanza su altura y separación respecto a las mecánicas o serviles y surge la distinción entre oficios mayores y menores, pero las artes liberales nunca perderán su estatus heredado de la Antigüedad clásica.

El intelectual urbano del siglo XII se considera y se siente como un artesano, como un hombre de oficio comparable a los otros habitantes de la ciudad. Su función es el estudio y la enseñanza de las Artes liberales. Pero ¿qué es un arte? No es una ciencia, es una técnica. Ars es tekhné, es la especialidad del profesor así como el carpintero y el herrero tiene las suyas. (Le Goff, 1996, p. 68)

Oficio será ese espacio intermedio entre la techné y la poiesis. La palabra oficio viene de officium o también opficium. De opus (obra) y facere (hacer), y será íntimamente relacionada al concepto ars. Esta acepción puede verse en lo expresado por Tomás de Aquino en el siglo XIII, "Ars, recta ratio factibilium, y recta ratio agibilium"13. (Borrero Cabal, 2008, p. 42):

13 Correcto proceder en los actos internos y normas de la conducta. Esto derivado de la acepción de que el arte sugiere acción, pericia, técnica y belleza, pues se define como la facultad de prescribir normas para hacer las cosas con acierto. Es el puente entre la techné y la poiesis, esa techné griega surgida del mito. 
Según Hugo de Saint-Victor, en el siglo siguiente Santo Tomás extraerá todas las consecuencias de esta posición. Un arte es toda actividad racional y justa del espíritu aplicada la fabricación de instrumentos, tanto materiales como intelectuales; es una técnica inteligente del hacer. Ars este recta ratio factibilium. De manera que el intelectual es un artesano; "entre todas las ciencias (las artes liberales), se llaman Artes, pues implican no sólo el conocimiento sino también una producción que deriva inmediatamente de la razón, como la función de la construcción (la gramática), de los silogismos (la dialéctica), del discurso (la retórica), de los números (la aritmética), de las medidas (la geometría), de las melodías (la música), de los cálculos del curso de los astros (la astronomía)". (Le, Goff, 1996, p. 68)

Serán San Agustín de Hipona y San Jerónimo quienes superarán ese carácter mítico a un origen racional. Del primer autor, dos obras son fundamentales, Disciplinarum libri y De ordine; en el primero, un intento por hacer una gran enciclopedia de las artes liberales, mientras que el segundo es un esfuerzo por mostrar la genealogía racional e intelectual de las artes. Por su parte, San Jerónimo será quien planteará la perspectiva aún hoy conocida del trívium y quaedrivium.

Con Alcuíno de York, en pleno renacer carolingio, alcanzarán su auge dichas artes liberales. Bajo el decreto de Carlos Magno para crear escuelas en los episcopados para enseñar las Sagradas Escrituras y otras obras literarias, sin remuneración alguna, este irlandés traerá al imperio su experiencia en la escuela de York, mas dará un carácter propedéutico a las mismas. Será el inicio de las artes liberales, anexa a las escuelas y como formación general, que se constituirá con el tiempo en la formación inicial para el paso a las facultades. 


\section{El Estudio General en la Orden de Predicadores y la Universidad de Estudio General}

Era el siglo XI cuando Domingo de Guzmán funda la Orden de Predicadores y es confirmada por el papa Honorio III. Desde sus inicios estará el estudio como elemento fundamental del fraile, esto debido a la experiencia del buen sacerdote de Osma con el clero, religiosos y obispos que evidenciaban su poca formación y pobre capacidad discursiva y argumentativa frente a los grandes grupos heréticos como los Albigenses y Kátaros, además de religiones monoteístas que tomaban fuerza como los musulmanes y judíos.

[3.] Nell'estate 1217, quando ancora la prima comunità si andava consolidand, S. Domenico la disperdeva in piccoli gruppi: in Spagna, a Bologna e a Orleans - ma il gruppo più grande, di sette frati, lo invianva a Parigi (12), "ut studerent et predicarent et conventum ibi facerent" (13). Con quest'azione - la sola ordinata con autorità nella fondazione dell'Ordine - veniva instituita la missione universale dei Frati Predicatori e il significato centrale dello studio in questo nuevo Ordine ${ }^{14}$. (Senner, 2005, pp. 153, 154)

Dicha solicitud de apremiar el estudio en la formación de los futuros frailes estará presente desde las primeras Constituciones, así queda al menos reseñado:

14 [3.] En el año de 1217, cuando todavía era la primera consolidada comunidad, Santo Domingo dispersa en pequeños grupos en España, en Bolonia y Orleans - pero el mayor grupo, de siete hermanos, es enviado a París (12), "para estudiar y predicar y que tiene que hacer en el convento" (13). Con esta acción — la orden con autoridad en la fundación - se instituyó la misión universal de los Frailes Predicadores y la importancia central del estudio en la presente Orden Nuevo. [Traducción propia]. 
Si ratio studiorum in constitutionibus anni 1228 attenditur, tempus studio assignandum vel ex recitatione officii ecclesiastici breviter et succincte absolvendi repetiturl. Insuper "circa eos qui student taliter dispensetur a praelato, ne propter officium vel aliud de facili a studio retrahantur vel impediantur". ${ }^{15}$ (Walz, 1924, p, 124)

Mas su esplendor estará contemplado y expresado en la ratio studiorum o razones del estudio o para el estudio, afirmación del espíritu y carisma de la Orden de Predicadores, enunciación de lo que serían posteriormente los estudios generales al interior de los hijos de Domingo. El mismo Lobato lo manifiesta en un documento llamado Filosofia y "sacra doctrina" en la escuela dominicana del S. XIII, documento entregado y con dedicatoria a los estudiantes durante su curso Filosofía - Teología en Colombia, durante su visita al estudiantado dominicano de Bogotá, con fecha del 22 de agosto de $2001^{16}$ :

Esta concepción del servicio que la filosofía, como obra de la razón, puede prestar a la teología, puesta en práctica en la obra de Tomás y expuesta de muchos modos en los diversos tratados, logró tener acogida y pasó a la legislación de la Orden en el Capítulo general del año 1259, tenido en Valencia (72). Tomás

15 Si se tiene en cuenta el plan de estudios de las constituciones del año 1228, el tiempo asignado al estudio se obtiene inclusive de la recitación del oficio eclesiástico que bebe cumplirse breve y sucintamente. Además, "en relación con los que estudian que las cosas se organicen por el superior de tal manera que por razón del oficio o de alguna otra cosa no se alejen ni se vean impedidos en cuanto al estudio". [Traducción de Noel Olaya Perdomo y Dayán Herrera Bernal]

16 Publicado en, revista Angelicum, vol. 71. (1994) pp. 3-42. 
no era capitular, pero fue invitado como miembro de una comisión de estudios, integrada por cinco maestros: Bonhomme, Fiorenzo de Hesdin, Pedro de Tarentaise, Alberto Magno y Humberto de Romanis. La comisión recibió el encargo de redactar una cierta ratio studiorum, la primera de este género en la historia de la Orden. La comisión llevó a cabo su cometido con una competencia indiscutible. En la nueva Ratio se refleja la situación cultural y se da una orientación apropiada a la vocación de estudio y del cultivo de la teología de la Orden. (Lobato, 2001, p. 75)

La importancia de esta cita radica en el cambio de perspectiva al interior de la Orden y la configuración del ambiente propicio para los estudios generales al interior de la comunidad, pues como expresa el mismo Franklin Buitrago, O. P. en el documento ya señalado, muchos hombres se mostraron hostiles al estudio de ciencias distintas a la sagrada teología, y que se expresa de la siguiente manera en la primera Constitución,

Pro diebus dominicis et festis praecipuis ardor studii in eo temperatur, quod tunc fratres "a quaternis scribendis se abstineant"3. "Quoniam circa studentes diligens est adhibenda cautela" "praeponitur eis aliquis frater specialis (magister studentium) pro moderatione eorum in studii" 4 . Si quadrivium pro studentibus nostris non requirebatur 5 , materia studii in ordine non erant scientiae saeculares "nec etiam artes quas liberales vocant nisi aliquando circa aliquos magister ordinis vel capitulom generale voluerit alister dispensare, sed tantum libros theologicos tam iuvenes quam alii legant". "In libris gentilium et philosophorum non studeant etsi ad horam inspiciant"”17. (Walz, 1924, p. 124)

17 Por razón de los días domingos y de las fiestas principales, se modera el ardor del estudio porque entonces los frailes "deben abstenerse de escribir en 
Será gracias a Humberto de Romanis, quinto maestro de la Orden, que los dominicos adquirirán definitivamente el aire intelectual que los caracteriza y entrarán de lleno a las artes liberales y al aporte de dicha comisión en su momento, pero también será, como ha dicho Lobato, reflejo de la situación cultural, o en palabras de Abel Salazar:

Con la aparición de las Ordenes mendicantes entramos en una nueva era. Sus religiosos frecuentan las Universidades y reciben en esto el apoyo de la Sede Apostólica (43); a imitación de las mismas organizan sus estudios generales y particulares, de modo que a mediados del siglo XIII todos los conventos de la Orden de Predicadores y muchos de la de los Menores se halla[n] erigidos en centros de estudios eclesiásticos (44), y más tarde, después de la fundación de la Compañía de Jesús, varios Colegios de las Órdenes religiosas obtienen privilegios universitarios (45). (Abel, 1946, p. 15)

En palabras de Buitrago, O.P., "desde entonces muchos conventos se convertirán en escuelas de teología imitando las características y la nomenclatura de los Studium Generale universitarios". Dichos estudios se expresaban en tanto ratio formationis particularis y ratio formationis

el cuaderno" (3). "Ya que hay que tener un cuidado diligente en relación con los estudiantes los preside algún un hermano especial, a saber, el maestro de estudios para dirigir sus estudios" (4). Si no se necesitaba (5) el cuadrivio para nuestros estudiantes la materia de estudio en la orden no eran las opiniones mundanas "ni siquiera las artes que llaman liberales, a no ser que de vez en cuando acerca de algunos temas el maestro de la orden o al capítulo general quisiera ordenar algo distinto, sino solamente deben leer libros de teología tanto los jóvenes como los demás". "Que no se dediquen a los libros de los gentiles y de los filósofos, aunque los miren a la hora indicada". [Traducción de Noel Olaya Perdomo y Dayán Herrera Bernal]. 
generalis, la Studia Provincialia (solemnia) y el Studium Generale, pero a su vez se encontraba la categoría de Estudios Eclesiásticos Superiores ${ }^{18}$ para diferenciarlos de los estudios superiores no eclesiásticos o profanos. Para el caso de los Estudios Generales de la Orden de Predicadores, según Abel Salazar (1946, p. 101) ${ }^{19}$, hubo tres tipos de casas de estudio: estudios conventuales, estudios solemnes y estudios generales o universidades.

Los primeros eran todos los conventos de la Orden, pues no era permitida la erección de ninguno mientras no estuviera dotado de lector público o doctor, como se establecía en las Constituciones. Los segundos eran, por lo regular, uno o dos en cada Provincia, para que confluyesen en ellos los hijos de esta. En cuanto a los privilegios y las reglas, se asimilaba a los estudios generales o universidades. Los últimos ocupaban el grado sumo en los estudios de la Orden, y a ella se dirigían a perfeccionarse la flor y nata de la juventud estudiosa; quienes después habrían de desempeñar las cátedras y otros cargos de relieve (Abel, S. 1946, p. 101).

Los Studium Generale de los dominicos serán plasmados sobre los estatutos de la Universidad de París y lograrán todo su rasgo de una corporación universitaria por tener una apertura a maestros y estudiantes de todo el mundo. Su calidad y apertura, así como agregación oficial a una universidad pública, les hará merecedores del derecho a preparar doctores en teología. Estos rasgos le harán más proximo a una facultad de teología que a un seminario o convento y signficará una ruptura y novedad radical dentro de los estudios eclesiáticos si se les compara con las escuelas catedralicias y monacales.

18 Clasificación utilizada por fray José Abel Salazar, en su obra Los estudios eclesiásticos superiores en el Nuevo Reino de granada (1536-1810).

19 Cfr. Angelus Walz, Compendium historiae Ordinis Predicatorum, pp. 125-130. 
Entonces, como se ha indicado, los Estudios Generales eran más cercanos a las escuelas que a la universidad, o como establece Franklin Buitrago, O. P., el Estudio General Dominicano guarda una estrecha cercanía a la relación fundacional de la universidad. Por su parte, Borrero, al describir dicho origen, también enuncia, en tanto el sentido etimológico de la universitas, que la universidad es traducción directa de universitas y esta refiere a multitud de cosas, pues es unidad y convergencia, unidad en lo diverso y plural. En esta línea, fray Franklin Buitrago, O. P afirma: "Universitas porque reúne y articula el universo de conocimiento de su época, universitas porque en ella se congregan académicos de todo el orbe cristiano... Las universidades nacen de los Studium Generale o Estudios Generales" (Fray Buitrago Rojas, O. P., p. 40).

Hablar de universidad de estudio general refiere a la condición de apertura y diálogo. Apertura en tanto acceso a la realidad como totalidad, donde la convergencia de las disciplinas es un componente fundamental. El mundo ya no tiene una sola cara y podría mediante un permiso de laxitud llevarse a los nuevos paradigmas epistemológicos, al principio de complejidad o complementariedad, a conceptos como inter y transdisciplinariedad, a la tendencia a los sistemas abiertos, a la ontología sistémica y a la metacomunicación del lenguaje total.

\section{Referencias}

Abel Salazar, J. (1946). Los estudios eclesiásticos superiores en el Nuevo Reino de Granada (1563-1810). Madrid: Consejo Superior de Investigaciones Científicas. Beuchot, M. (2004). Introducción a la filosofia de santo Tomás de Aquino. 2a. Salamanca: San Esteban.

Borrero Cabal, A., S. J. (2008). La universidad. Estudios sobre sus orígenes, dinámicas y tendencias. Vol. I. Bogotá: Universidad Javeriana. 
Chantraine, P. (1977). Dictionnaire étymologique de la langue grecque . 4-I (P-Y). Paris: Klincksiek.

Fray Buitrago Rojas, F., O. P. (2003). El Studium Generale: un lugar de encuentro entre la revelación y las ciencias del hombre. Optantes: Revista de los Frailes Estudiantes Dominicos de Colombia (24), 40-48.

Le Goff, J. (1996). Los intelectuales en la Edad Media. Barcelona, España: Gedisa.

Lo-Cicero, G., O. P. y Vicenti Jandel, A., O. P. (1862). Constitutiones Declarationes et Ordinationes: Capitulorum Generalium Sacri Ordinis Fratrum predicatorum. Ab anno 1220 usque ad 1650 emanatae. Roma: Ex Typographia Bernardi Morinsi.

Lobato, A., O. P. "Filosofía y 'Sacra Doctrina' en la escuala dominicana del s. XIII”. Bogotá, 22 de agosto de 2001. 1-4. Fotocopia.

Senner, W., O. P. (2005). Gli Studia Generalia nell'Ordine dei Predicatori nel duecento. Roma: Grottaferrata. Copias.

Walz, A. (1924). Compendium historiae Ordinis Predicatorum. Roma: Herder. 
